\title{
Forensic telepsychiatry : a possible solution for South Africa?
}

\author{
M Mars', S Ramlall'2, S Kaliski ${ }^{3}$ \\ 'Department of TeleHealth, University of KwaZulu-Natal, Durban, South Africa \\ 2Department of Psychiatry, University of KwaZulu-Natal, Durban, South Afric. \\ ${ }^{3}$ Department of Psychiatry and Mental Health, University of Cape Town, Cape Town, South Africa
}

\begin{abstract}
Objective: South Africa has a shortage of facilities and psychiatrists to assess adjudicative competence of prisoners awaiting assessment under sections 77 to 79 of the Criminal Procedures Act of 1977. Various solutions have been proposed by the Department of Health. The recent linking of a Magistrate's court and a prison by videoconferencing offers the opportunity to implement a forensic telepsychiatry service. The literature on forensic telepsychiatry for assessment of adjudicative competence was reviewed. Method: The electronic databases, PubMed, Scopus, Cinahl and Google Scholar were searched for papers on forensic telepsychiatry. The inclusion criterion was papers reporting the use of videoconferencing for assessment of adjudicative competence or for assessment for referral out of the judicial system, by psychiatrists or psychologists. Results: 411 papers were found of which 13, published between 1997 and 2008 were relevant. The use of videoconferencing for forensic psychiatric assessment was reported from four countries. The courts in those jurisdictions have accepted the use of videoconferencing for assessment and no successful appeals have been mounted on the basis of the use of videoconferencing for assessment. User satisfaction has not been reported for assessing adjudicative competence. Forensic telepsychiatry has been found to be cost effective, improve access to scarce specialist skills and reduce transport of prisoners under guard to hospitals or psychiatrists to prisons. Conclusion: There is nothing in the literature to suggest that a forensic telepsychiatry service is not feasible in South Africa and a pilot project is being planned.
\end{abstract}

Keywords: Videoconferencing; Telemedicine; Forensic psychiatry; South Africa

Received: 09-10-2011

Accepted: 16-02-2012

doi: http://dx.doi.org/10.4314/ajpsy.v15i4.31

\section{Introduction}

The prevalence of serious mental disorders is higher among prisoners than in the general population. ${ }^{1}$ With approximately lpsychiatrist per 100,000 people, there are too few psychiatrists in South Africa to meet the country's needs. There are even fewer psychiatrists involved in forensic psychiatry and offenders requiring psychiatric assessment of adjudicative competence are frequently held in prisons for some time before psychiatric assessment can be undertaken.

In 2007, the Criminal Justice Review Committee requested the South African Department of Health (DOH) to investigate the delay of trials of awaiting trial prisoners referred by the Courts for 30 days of psychiatric observation in a mental institution in terms of sections 77, 78 \& 79 of the Criminal Procedure Act No 51 of 1977. In March of 2010 there were 735



pre-trial detainees awaiting observation in South Africa with onlyl 68 beds available in 11 mental institutions. The time to observation in one Province was 15 months. ${ }^{2}$ At that time there were an estimated 38 psychiatrists in the public sector and 25 from the private sector who were available and willing to participate in undertaking psychiatric observations. ${ }^{2}$ This constitutes roughly 10\% of the psychiatrists registered with the Health Professions Council of South Africa and is a reflection of the shortage of psychiatrists in the country.

An article in the Cape Times on 9 May 2005 headlined that the brain drain from this country had led to a shortage of psychiatrists offering forensic services. The lack of child and adolescent psychiatrists is even more desperate. In the Western Cape only one child psychiatrist is available to conduct forensic assessments, whereas the demand for assessments of juveniles is increasing, and, more alarmingly, the offences for which these individuals are being charged are usually violent in nature.

The DOH has recently developed, "A turnaround strategy to reduce the long waiting list and waiting period for forensic psychiatric observations/evaluation.." Key recommendations are that observations can, under some circumstances, be 
undertaken by a single psychiatrist and not a panel of psychiatrists and that observation does not have to be performed in a mental institution but can take place in an outpatient setting or in prisons. ${ }^{2}$

A pilot project linking a magistrate's court and a prison by videoconference has recently been implemented in Cape Town. The project aims to reduce prisoner transfers to the court, free correctional services staff from escorting prisoners, and improve security. The provision of videoconferencing equipment in a prison affords the opportunity of establishing a forensic telepsychiatry service at the prison. Forensic telepsychiatry has been defined as "the use of telecommunication technology to provide mental health services in a medico-legal context."3 This definition covers forensic evaluations, clinical consultations and education. ${ }^{4}$

The aim of this paper is to review the literature on forensic telepsychiatry with specific reference to pre trial forensic evaluation of adjudicative competence with a view to implementing a pilot forensic telepsychiatry project.

\section{Method}

Searches were made of PubMed, Scopus and CINAHL electronic databases. Various search strategies were used. For Pubmed: (("telemedicine"[MeSH Terms] OR "telemedicine"[All Fields] OR Telepsychiatry[All Fields] ) AND ("forensic psychiatry"[MeSH Terms] OR "forensic psychiatry"[All Fields])) returned 317 abstracts which were reviewed and relevant full length papers in English obtained and, ("Telemedicine"[All Fields] OR "Telecommunication"[All Fields] OR "Videoconference"[All Fields] OR "electronic mail"[All Fields] OR "computer communication networks"[All Fields] OR "remote consultation"[All Fields]) AND ("Forensic Psychiatry"[All Fields] OR ("Forensic"[All Fields] AND "Psychiatry"[All Fields]) which returned 17 abstracts and all papers were obtained.

The SCOPUS search on ALL(("forensic psychiatry" OR (forensic AND psychiatry)) AND (videoconference OR videoconferencing)) returned 51 abstracts which were reviewed and relevant papers obtained. The CINAHL search using the same search strategy returned 26 papers which were obtained and reviewed.

Google Scholar was searched on, "Forensic Telepsychiatry", "Forensic Psychiatry and Videoconference".

The review process sought to find papers, in English, relating to the use of videoconferencing in the judicial system for assessment of adjudicative competence or for assessment for referral out of the judicial system, by psychiatrists or psychologists. Papers relating to telepsychiatric services provided to prisons, jails and adolescent correctional facilities for all other aspects of mental health care were excluded.

\section{Results}

Thirteen papers, two of which were reviews, met the inclusion criteria. Papers were published between 1997 and 2008. Five were from the US ${ }^{5-9}$, four from Australia ${ }^{1,10-12}$, three from the United Kingdom ${ }^{4,13,14}$ and one from Canada. ${ }^{15}$

The first reported use of videoconferencing to perform psychiatric assessment in terms of national or state mental health acts was in Australia, in 1993 in the States of New South Wales and South Australia and involved four patients already known to the specialist psychiatrist. ${ }^{11}$

The use of forensic telepsychiatry and reports related to its use are dependent on the legal and licensure systems of the state or nation in which it is used. In Australia, videoconferencing is used in forensic psychiatry for "court diversion", which is the transfer of mentally ill people from the criminal justice system to hospital and or community mental health placements, or "court liaison" which includes court diversion and also "linking, brokering and advocating for appropriate care." " One of the aims of the court liaison system is to identify mentally ill offenders and direct them to a mental health practitioner. This process can begin at the time of arrest and can result in a Hospital Order requiring a defendant to be detained in an authorized hospital for up to seven days for psychiatric assessment.

By 1998, two forensic telepscychiatric assessments were being made per month in rural Queensland. ${ }^{10}$ In Western Australia videoconferencing is used to assess patients in rural and remote areas if a hospital order is being considered. In 2003, the first year of service, 28 of 47 Hospital Order Assessments (60\%) made from rural and remote courts were performed by videoconference. ${ }^{1}$ By 2008 , Sullivan et al noted that, "Videoconferencing is in common use in Australian forensic mental health services" and that "videoconferencing technologies are critical to effective forensic mental health services in Australia." 12

In the United States, the assessment of adjudicative competence can involve the use of assessment tools in addition to clinical examination. There have been several reports comparing the validity and satisfaction of both psychiatrists and prisoners when using various assessment tools by videoconferencing or face to face. These include the Global Severity Index of the Brief Symptom Inventory ${ }^{8}$, the MacArthur Competence Assessment Tool ${ }^{7}$, the Brief Psychiatric Rating Scale and the Georgia Court Competency Test - Mississippi State Hospital Revision ${ }^{5}$, as part of the clinical assessment. Reports of services offering assessment of competency to stand trial are limited. A pilot Forensic Telepsychiatry programme in South Carolina started in 2001 and undertook 28 evaluations of adjudicative competency and in the US Army, three assessments had been made by $2006 .{ }^{6}$

In Canada there were 14 telepsychiatry programmes in 2001, six of which offered forensic services. ${ }^{15}$ Whether all of these services included assessment of competency to stand trial is not stated.

The United Kingdom has been slower to implement forensic telepsychiatry. Three papers have come from one group ${ }^{4,13,14}$, who introduced a forensic telepsychiatry service in Nottingham in 2005, with 30 assessments in the first year. ${ }^{14}$

There are no reports of patient and clinician satisfaction when using videoconferencing for assessing adjudicative competence. Patients were satisfied with the use of videoconferencing for completing assessment tools ${ }^{5,8}$ while clinicians were less satisfied. ${ }^{5}$

\section{Discussion}

The term telepsychiatry was first used by Dwyer in 1973 to describe psychiatric consultation by interactive television between general practitioners and psychiatrists at two centres, $180 \mathrm{~km}$ apart ${ }^{16}$, but clinical and educational use of closed circuit television (CCTV) in psychiatry preceded this 
by 20 years. Tucker, in California, used CCTV for mass therapy to overcome the problem of overcrowding and staff shortages in mental hospitals in 1953. ${ }^{17}$ At the Nebraska Psychiatric Institute, Wittson and Dutton used CCTV for education and clinical consultation in the 1950s. ${ }^{18}$

In the contexts of assessment of competence to stand trial or early identification of mental illness and diversion from the judicial system, as in the court diversion system in Australia, forensic telepsychiatry is currently limited to a few developed world countries. These services all appear to be driven by common needs, such as the high prevalence of mental illness among offenders ${ }^{1}$, poor facilities to manage mental illness in prisons, the shortage of beds assigned to the mentally ill in secure hospitals ${ }^{1,19}$, the shortage of skilled professionals to conduct forensic assessments which is worse in remote and rural areas ${ }^{4,6,7,9,19}$, and the practice of siting correctional facilities in rural areas. These are problems common to South Africa and many other African countries.

Forensic telepsychiatry addresses some of these problems. It improves timely access to specialist skills ${ }^{1,4,9,12,19,20}$, reduces costly transportation and escort of prisoners to urban areas and specialist hospitals for assessment, or transport of specialists to correctional facilities $1,7,10,12,19$, reduces unnecessary or inappropriate admission to hospitals ${ }^{12}$, and reduces risk to psychiatrists by allowing them to perform assessments without having to enter prisons or secure hospitals.

\section{Cost}

It is generally held that there are significant cost savings in telepsychiatry and forensic telepsychiatry ${ }^{1,10,21}$ but some have identified set up and running costs as barriers to implementation. ${ }^{12}$ Costs can be contained by using existing infrastructure for other activities such as education, administrative meetings, other judicial activities and other clinical services 4,9,10,12,15,22,23 and avoidance of establishing stand alone forensic telepsychiatry services. In the United Kingdom ${ }^{4}$, Australia ${ }^{1,11}$ and in many states in the US ${ }^{5}$, courts and prisons already have videoconferencing facilities used for judicial purposes and advantage is taken of this. All medical schools in South Africa have access to videoconferencing and rapid advances in technology are making wireless desktop videoconferencing a cheaper option.

There are few sound cost analyses of telemedicine ${ }^{24}$ and forensic telepsychiatry is no exception. An early study in Queensland estimated an annual saving of AU\$ 96,000 per annum for the Flying Doctor Service through the implementation of the telepsychiatry service. The travel, personnel and call costs for the forensic telepsychiatry component of the service were $14 \%$ of the cost of the regular service. ${ }^{10}$ Allied to savings in transport are the benefits of not having to deploy prison staff to escort prisoners travelling for assessment and the related risk to the community of escape.

\section{Guidelines}

Sullivan correctly points out that there are a number of situations where videoconferencing cannot replace direct assessment. ${ }^{12}$ What is needed is clear definition of these instance ${ }^{25}$ and the development of guidelines for the practice of forensic telepsychiatry. The point is made that unless health professionals develop evidence based standards and practice guidelines for themselves, Government or other regulatory bodies will do so $^{25,26}$ and these may not necessarily be appropriate. In 1998, the American Psychiatric Association published a resource document on the use of videoconferencing in telepsychiatry. ${ }^{27}$ In Australia guidelines for forensic telepsychiatry were developed in the State of Victoria in the late 1990's which address issues of privacy, confidentiality, treatment standards, equipment standards and the role of the rural worker. ${ }^{23}$

\section{Limitations}

A number of potential limitations of forensic telepsychiatry have been noted. The presence of correctional services personnel during consultation affects privacy and confidentiality as do poorly soundproofed rooms. ${ }^{12,28}$ Some nuances like restless legs beneath the desk may be missed unless the clinician is skilled in the use of the pan, tilt and zoom features of videoconferencing cameras and the technology cannot provide smell. ${ }^{1}$ There are concerns about technology failure during interviews.

Some have seen videoconferencing as a benefit and have suggested that videoconferencing changes the patient clinician relationship to the benefit of the patient by altering the power differential that exists in a face to face office interview. ${ }^{5,12}$

Other possible limitations may include difficulties in conducting intricate cognitive tests, risk assessment, and generally being able to establish rapport with noncommunicative individuals. It may also be important to differentiate between those charged with relatively minor offences (for whom telepsychiatry may be most appropriate) and those with serious offences.

\section{Legal and Ethical issues}

Legal and ethical issues are always raised when telemedicine services are offered. These include licensure, liability, informed consent, confidentiality, privacy, record keeping, prescription and data security and storage. 4,5,9,12,26 Licensure is an issue in those countries where practitioners are limited to practice in only certain jurisdictions within the country, such as in the United States. It is also an unresolved issue in the international practice of telemedicine across borders. ${ }^{26}$ Whether practitioners should be separately certificated or licensed to practice their discipline of telemedicine was a debate which is receding as telemedicine use increases. What is required is that practitioners are competent in the use of their equipment and understand its shortcomings. Informed consent should be obtained, but this can be difficult in multilingual countries like South Africa with eleven official languages some of which do not have words in their lexicons for the technology and concepts involved. The problem is exacerbated when consent has to be obtained through an interpreter. ${ }^{26}$ Data security and storage are commonly dealt with in national information and communication laws and these need to be adhered to.

\section{Court Acceptance}

Unsurprisingly, forensic telepsychiatry has been accepted by the courts in those countries reporting its use. Miller, in 2008, found limited case law on telemedicine and telepsychiatry in the 
US. In those cases in which State and Federal prisoners had been involved in telemedicine or telepsychiatry, none attacked either the doctor involved or the use of videoconferencing. ${ }^{9}$ In the US Military, one case was reported in which the use of videoconferencing was the basis of an appeal and, "The court ruled that the use of videoconferencing for a mental competency hearing did not violate due process and that there was no legal basis for appeal based on interview modality." 6,9 In the UK, Saleem states that, "...information attained during psychiatric interview will not be undermined by the legitimacy of video link as a means of interview" and goes on to quote the senior Presiding Judge for England and Wales on the use of telepsychiatry, "I can see no basis on which a sensible legal challenge to the process could be mounted, provided the interviews are conducted in circumstance of confidentiality and there are no issues over sufficiency of time and ability to communicate." 4

\section{Conclusion}

The use of forensic telepsychiatry for the assessment of adjudicative competence is both relevant and appropriate in the South African context. The recommendations of the Department of Health's "Turn Around Strategy" and the introduction of videoconferencing facilities to prisons will facilitate this. There is nothing in the literature to suggest that forensic telepsychiatry will not be achievable in South Africa. What is needed is implementation of a controlled clinical trial of forensic telepsychiatry. This will require training of psychiatrists and staff in correctional facilities on the use of videoconferencing for telepsychiatry, development of standard operating procedures, and a change management strategy. As technology advances, the limitations imposed by poor but expensive connectivity in South Africa and Africa are being eroded by cellular telephony. The growing use and availability of $3 \mathrm{G}$ networks is making desktop videoconferencing over cellular networks a reality. Pragmatic solutions are required to reduce the delays in forensic assessment in South Africa, of which forensic telepsychiatry is one.

\section{References}

1. Brett A, Blumberg L. Video-linked court liaison services: forging new frontiers in psychiatry in Western Australia. Australasian Psychiatry 2006; 14:53-56.

2. Dept Of Health Republic of South Africa, A turnaround strategy to reduce the long waiting list and waiting period for forensic psychiatric observations/evaluations of awaiting trial detainees referred by courts in terms section 77, 78 \& 79 of the Criminal Procedure Act no 51 of 1977: 2010:1-14.

3. Merideth P. Forensic applications of telepsychiatry. Psychiatric Annals 1999;29:429-431.

4. Saleem Y, Taylor MH, Khalifa N. Forensic telepsychiatry in the United Kingdom. Behav Sci Law 2008;26:333-344.

5. Manguno-Mire GM, Thompson Jr JW, Shore JH, Croy CD, Artecona JF, Pickering JW. The use of telemedicine to evaluate competency to stand trial: A preliminary randomized controlled study. Journal of the American Academy of Psychiatry and the Law 2007;35:481-489.

6. Schneider BJ. Forensic telepsychiatry in the US Army. Telemedicine and eHealth 2006;12:222.

7. Lexcen FJ, Hawk GL, Herrick S, Blank MB. Use of video conferencing for psychiatric and forensic evaluations. Psychiatr Serv 2006;57:713-715.

8. Brodey BB, Claypoole KH, Motto J, Arias RG, Goss R. Satisfaction of forensic psychiatric patients with remote telepsychiatric evaluation. Psychiatr Serv 2000;51:1305-1307.

9. Miller TW, Clark J, Veltkamp LJ, Burton DC, Swope M. Teleconferencing model for forensic consultation, court testimony, and continuing education. Behav Sci Law 2008;26:301-313.

10. Trott P, Blignault I. Cost evaluation of a telepsychiatry service in northern Queensland. Journal of Telemedicine and Telecare 1998;4:66-68.

11. Yellowlees PM. The use of telemedicine to perform psychiatric assessments under the Mental Health Act. Journal of Telemedicine and Telecare 1997;3:224-226.

12. Sullivan DH, Chapman M, Mullen PE. Videoconferencing and forensic mental health in Australia. Behav Sci Law 2008;26:323-331.

13. Khalifa N, Saleem Y, Stankard P. The use of telepsychiatry within forensic practice: A literature review on the use of videolink. Journal of Forensic Psychiatry and Psychology 2008;19:2-13.

14. Stankard P, Younus S. Forensic telepsychiatry. Psychiatric Bulletin 2007;31:155.

15. Urness D, Hailey D, Delday L, Callanan T, Orlik H. The status of telepscyhiatry services in Canada: a national suvey. Journal of Telemedicine and Telecare 2004;10:160-164.

16. Dwyer TF. Telepsychiatry: psychiatric consultation by interactive television. Am J Psychiatry 1973;130:865-869.

17. Tucker W, Olfson M, Simring S, Goodman W, Bienenfeld S. A pilot survey of inmate preferences for on-site, visiting consultant, and telemedicine p.sychiatric services. CNS Spectr 2006;11:783-787.

18. Bashur RL, Shannon GW, History of Telemdicine : evolution context and transformation. New Rochelle, New York: Mary Ann Liebert Inc, 2009:1-413.

19. Manfredi L, Shupe J, Batki SL. Rural jail telepsychiatry: a pilot feasibility study. Telemed J E Health 2005; 1 1:574-577.

20. Fox KC, Somes GW, Waters TM. Timeliness and access to healthcare services via telemedicine for adolescents in state correctional facilities. J Adolesc Health 2007;41:161-167.

21. Harley J, McLaren P, Blackwood G, Tierney K, Everett M. The use of videoconferencing to enhance tertiary mental health service provision to the island of Jersey. J Telemed Telecare 2002;8 Suppl 2:36-38.

22. Paing WW, Weller RA, Welsh B, Foster T, Birnkrant JM, Weller EB. Telemedicine in children and adolescents. Curr Psychiatry Rep 2009;11:114-119.

23. Lessing K, Blignaut I. Mental heatlh telemedicne programmes in Australia. Journal of Telemedicine and Telecare 2001;7:317-323.

24. Davalos ME, French MT, Burdick AE, Simmons SC. Economic evaluation of telemedicine: review of the literature and research guidelines for benefit-cost analysis. Telemed J E Health 2009; 15:933-948.

25. Miller TW, Burton DC, Hill K, Luftman G, Veltkemp LJ, Swope M. Telepsychiatry: critical dimensions for forensic services. J Am Acad Psychiatry Law 2005;33:539-546.

26. Mars M, Jack C. Why is telemedicine a challenge to the regulators? South African Journal of Bioethics and Law 2010;3:55-58.

27. APA Board of Trustees, American Psychiatric Association resource document on telepsychiatry via videoconferencing: 1998:1-9.

28. Antonacci DJ, Bloch RM, Saeed SA, Yildirim Y, Talley J. Empirical evidence on the use and effectiveness of telepsychiatry via videoconferencing: implications for forensic and correctional psychiatry. Behav Sci Law 2008;26:253-269. 